\title{
Evaluating State Dependence and Subtype Selectivity of Calcium Channel Modulators in Automated Electrophysiology Assays
}

\author{
Yuri A. Kuryshev, Arthur M. Brown, Emir Duzic, and Glenn E. Kirsch \\ ChanTest Corporation, Cleveland, Ohio.
}

\begin{abstract}
Voltage-gated $\mathrm{Ca}^{2+}$ channels play essential roles in control of neurosecretion and muscle contraction. The pharmacological significance of $\mathrm{Ca}_{v}$ channels stem from their identification as the molecular targets of calcium blockers used in the treatment of cardiovascular diseases, such as hypertension, angina, and arrhythmia, and neurologic diseases, such as pain and seizure. It has been proposed that state-dependent $\mathrm{Ca}_{v}$ inhibitors, that is, those that preferentially bind to channels in open or inactivated states, may improve the therapeutic window over relatively state-independent $\mathrm{Ca}_{v}$ inhibitors. High-throughput fluorescent-based functional assays have been useful in screening chemical libraries to identify $\mathrm{Ca}_{v}$ inhibitors. However, hit confirmation, mechanism of action, and subtype selectivity are better suited to automated patch clamp assays that have sufficient capacity to handle the volume of compounds identified during screening, even of modest sized libraries $(\leq 500,000$ compounds), and the flexible voltage control that allows evaluation of state-dependent drug blocks. lonWorks ${ }^{\mathrm{TM}}$ Barracuda (IWB), the newest generation of lonWorks instruments, provides the opportunity to accelerate the $\mathrm{Ca}_{v}$ drug discovery studies in an automated patch clamp platform in 384-well format capable of medium throughput screening and profiling studies. We have validated $h C a_{v} 1.2, h C a_{v} 2.1, h C a_{v} 2.2$, and hCav3.2 channels assays on the IWB platform (population patch clamp mode) and demonstrated that the biophysical characteristics of the channels (activation, inactivation, and steady-state inactivation) obtained with the IWB system are consistent with known subtype-specific characteristics. Using standard reference compounds (nifedipine, BAY K8644, verapamil, mibefradil, and pimozide), we demonstrated subtype-selective and state- and use-dependent characteristics of drug-channel interactions. Here we describe the design and validation of novel robust highthroughput $\mathrm{Ca}_{v}$ channel assays on the IWB platform. The assays can be used to screen focused compound libraries for state-dependent $\mathrm{Ca}_{v}$ channel antagonists, to prioritize compounds for potency or to counterscreen for $\mathrm{Ca}_{v}$ subtype selectivity.
\end{abstract}

\section{INTRODUCTION}

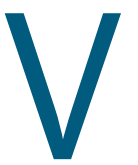
oltage-gated $\mathrm{Ca}^{2+}$-selective channels play essential roles in the control of neurosecretion and muscle contraction. The channels have been categorized as L-, N-, P/Q-, R-, or T-type based on functional and pharmacological properties. Sequence similarity has identified three subfamilies $\mathrm{Ca}_{\mathrm{v}} 1, \mathrm{Ca}_{\mathrm{v}} 2$, and $\mathrm{Ca}_{\mathrm{v}} 3$, where $\mathrm{Ca}_{\mathrm{v}} 1$ and $\mathrm{Ca}_{\mathrm{v}} 3$ correspond to L- and T-type, respectively. $\mathrm{Ca}_{\mathrm{v}} 2$ encompasses $\mathrm{N}-, \mathrm{R}-$, and $\mathrm{P} / \mathrm{Q}$ types. Each subtype contains a pore-forming $\alpha_{1}$-subunit accompanied by auxiliary subunits (e.g., $\alpha_{2} \delta, \beta_{1-4}$, and $\gamma$ ) that modify gating, subcellular trafficking, and drug binding characteristics. ${ }^{1}$

Development of drugs that act as calcium channel blockers has been successful for L-type channels in cardiovascular indications, for example, hypertension, heart failure, and atrial fibrillation. The success in this area has been due largely to state-dependent and usedependent characteristics of the drug-channel interaction such that the inhibitory effect is most pronounced at partially depolarized membrane potential, thus preserving normal function. ${ }^{2}$

Another area of calcium channel drug development has focused on neurologic disorders, including pain and epilepsy. Cav2.2 (N-type) has been identified as a valid pain target that can be inhibited by the selective blocker ziconotide to relieve chronic pain. ${ }^{3}$ However, recent development has centered on identifying state-dependent $\mathrm{Ca}_{\mathrm{v}} 2.2$ inhibitors, which preferentially bind to channels in open or inactivated states that may improve the therapeutic window over relatively state-independent $\mathrm{Ca}_{\mathrm{v}} 2.2$ inhibitors, such as ziconotide. ${ }^{4}$ Antiepileptic calcium channel inhibitors are exemplified by ethosuximide, broadly selective blockers of T-type (Cav3.x) channels. ${ }^{5}$ Another example is gabapentin, which inhibits Cav2.x trafficking through interaction with the $\alpha_{2} \delta_{1}$ auxiliary subunit and is approved for treatment of both seizures and pain. ${ }^{6}$

State- and use-dependent characteristics, and subtype selectivity of voltage-gated channels can be measured in a straightforward manner using patch clamp methods. Automated, high-throughput platforms are preferred in screening and profiling studies, but until recently, automated patch clamp instruments lacked the required levels of throughput and flexibility. Systems such as IonWorks ${ }^{\mathrm{TM}}$ Barracuda (IWB) that operate in a 384-well format can evaluate small chemical

(C) Kuryshev et al. 2014; Published by Mary Ann Liebert, Inc. This Open Access article is distributed under the terms of the Creative Commons Attribution Noncommercial License (http://creativecommons.org/licenses/by-nc/4.0/) which permits any noncommercial use, distribution, and reproduction in any medium, provided the original author(s) and the source are credited. 
libraries in the range of 20,000-100,000 compounds. In the present study, we show that state dependence and subtype selectivity can be readily assessed in IWB assays in recombinant cell lines that stably express L-, N-, P/Q, or T-type calcium channels.

\section{MATERIALS AND METHODS}

\section{Cell Lines}

Stable cell lines expressing (under tetracycline induction) human $\mathrm{Ca}_{\mathrm{v}} 1.2 / \beta_{2} / \alpha_{2} \delta_{1}$ (Chinese hamster ovary [CHO]; CACNA1C/CACNB2/ CACNA2D1), $\mathrm{Ca}_{\mathrm{v}} 2.1 / \beta_{4} / \alpha_{2} \delta_{1}(\mathrm{CHO} ;$ CACNA1A/CACNB4/CACNA2D1), $\mathrm{Ca}_{\mathrm{v}} 2.2 / \beta_{3} / \alpha_{2} \delta_{1}$ (CHO; CACNA1B/CACNB2/CACNA2D1), and $\mathrm{Ca}_{\mathrm{v}} 3.2$ (HEK293; CACNA1H) ion channels were constructed as described previously. ${ }^{7}$ CHO cells were maintained in Ham's F-12 CHO media supplemented with $10 \%$ fetal bovine serum, $100 \mathrm{U} / \mathrm{mL}$ of penicillin $\mathrm{G}$ sodium, $100 \mu \mathrm{g} / \mathrm{mL}$ of streptomycin sulfate, and the appropriate selection antibiotics. HEK293 cells were maintained in the Dulbecco's modified Eagle's medium/nutrient mixture F-12 (DMEM/F-12) supplemented with $10 \%$ fetal bovine serum, $100 \mathrm{U} / \mathrm{mL}$ of penicillin $\mathrm{G}$ sodium, $100 \mu \mathrm{g} /$ $\mathrm{mL}$ of streptomycin sulfate, and $500 \mu \mathrm{g} / \mathrm{mL}$ of G418 as the selection antibiotic. For experiments, the cells were passed in a medium lacking selection antibiotics 2-4 days. Expression was induced with tetracycline $16-14 \mathrm{~h}$ before recording. Verapamil at $3 \mu \mathrm{M}$ was included in the induction medium to avoid $\mathrm{Ca}^{2+}$ overload toxicity. Cell density was $\sim 50 \%-70 \%$ confluent at the time of harvest; two 150-mm plates $\left(\sim 1.2 \times 10^{7}\right.$ cells) were used per population patch clamp (PPC) experiment.

Cells were harvested by washing twice with 15-20 mL of Hank's Balanced Salt Solution (HBSS) and treatment with $5 \mathrm{~mL}$ of Accutase $^{\mathrm{TM}}$ (Innovative Cell Technologies, San Diego, CA) solution for 20 (CHO cells) or 60 (HEK293 cells) minutes. Cells were resuspended in a $50-\mathrm{mL}$ conical tube with addition of $10 \mathrm{~mL}$ of HBSS and triturated with a serological pipette to resuspend the cells and break up cell clusters. Cells were pelleted at $500 \mathrm{~g}$ for $2.5 \mathrm{~min}$, the supernatant was removed, and the cell pellet was resuspended in $10 \mathrm{~mL}$ of HBSS. The cell suspension was centrifuged again at $500 \mathrm{~g}$ for $2.5 \mathrm{~min}$ and the supernatant removed. Finally, the cell pellet was resuspended in $5 \mathrm{~mL}$ of HEPES-buffered physiological saline (HB-PS).

\section{Solutions and Electrophysiological Procedures}

Chemicals used in a solution preparation were purchased from Sigma-Aldrich (St. Louis, MO) and were of ACS reagent grade purity or higher. Stock solutions of test articles were prepared in dimethyl sulfoxide (DMSO) and stored frozen. Each test article formulation was sonicated (Model 2510/5510; Branson Ultrasonics, Danbury, CT) at ambient room temperature for $20 \mathrm{~min}$ to facilitate dissolution. Test article concentrations were prepared fresh daily by diluting stock solutions into extracellular solutions (HB-PS buffer). The solution composition was $137 \mathrm{mM} \mathrm{NaCl}, 4 \mathrm{mM} \mathrm{KCl}, 7 \mathrm{mM} \mathrm{CaCl}, 1 \mathrm{mM} \mathrm{MgCl}$, $10 \mathrm{mM}$ HEPES, and $10 \mathrm{mM}$ glucose, $\mathrm{pH}$ adjusted to 7.4 with $\mathrm{NaOH}$. All test and control solutions contained 0.3\% DMSO and 0.05\% F-127. The test article formulations were prepared in 384-well compound plates using an automated liquid handling system (Cyclone, Caliper). The internal HEPES-buffered solution consisted of $90 \mathrm{mM} \mathrm{CsF}$, $50 \mathrm{mM} \mathrm{CsCl}, 2 \mathrm{mM} \mathrm{MgCl}_{2}$, $0.5 \mathrm{mM}$ EGTA, and $10 \mathrm{mM}$ HEPES, pH 7.2 adjusted with $\mathrm{CsOH}$. A stock solution of amphotericin $\mathrm{B}$ was prepared in DMSO $(30 \mathrm{mg} / \mathrm{mL})$ and added to the solution at a final concentration of $100 \mu \mathrm{g} / \mathrm{mL}$. An extracellular buffer was loaded into the PPC plate wells ( $11 \mu \mathrm{L} /$ well) and a cell suspension was added into the wells (9 $\mu \mathrm{L} /$ well). After establishment of a whole-cell configuration (a 10-min perforation), membrane currents were recorded by on-board patch clamp amplifiers in IWB. The data acquisition frequency was $5 \mathrm{kHz}$. Inward peak current amplitudes were measured. Under these conditions, each assay was completed in $45 \mathrm{~min}$, and 5-10 experiments could be conducted each day.

\section{Data Analysis}

Initial data acquisition and analyses were performed using the IWB system operation software (version 2.0.2; Molecular Devices Corporation, Union City, CA). Data were corrected for leak current. The decrease in current amplitude after test article application was used to calculate the percent block relative to control. Results for each test article concentration $(n=3-4)$ were averaged, mean and standard deviation values were calculated and used to generate dose-response curves in XLfit add-in for Excel 2003 (Microsoft, Redmond, WA).

Drug effects were calculated as follows:

$$
\% \text { Block }=\left[\frac{\left(1-\mathrm{I}_{\mathrm{TA}}\right)}{\mathrm{I}_{\text {Baseline }}}\right] \times 100 \%,
$$

where $\mathrm{I}_{\mathrm{B} a s e l i n e}$ and $\mathrm{I}_{\mathrm{TA}}$ were the current amplitudes measured at baseline (before addition of a test article) and in the presence of a test article (or vehicle control), respectively.

If not specified, the data were corrected for run-down using the following equation:

$$
\% \text { Block }^{\prime}=100 \%-\left[(\% \text { Block }-\% \mathrm{PC}) \times \frac{100 \%}{\% \mathrm{VC}-\% \mathrm{PC}}\right],
$$

where $\% \mathrm{VC}$ and $\% \mathrm{PC}$ were the mean values of the current inhibition with the vehicle and positive controls, respectively; inhibition by saturating concentrations of nifedipine $\left(\mathrm{Ca}_{\mathrm{v}} 1.2\right)$ or mibefradil $\left(\mathrm{Ca}_{\mathrm{v}} 2.1, \mathrm{Ca}_{\mathrm{v}} 2.2, \mathrm{Ca}_{\mathrm{v}} 3.2\right)$ was used as \%PC value.

The concentration-response data for inhibitors were fit to an equation of the following form:

$$
\% \text { Block }=\frac{100 \%}{1+\left([\text { Test }] / \mathrm{IC}_{50}\right)^{N}},
$$

\section{Table 1. Acceptance Criteria for Wells}

\begin{tabular}{l|c} 
Parameter & Acceptance criterion \\
\hline$R_{\text {SEAL }}$ (baseline) & $>300 \mathrm{M} \Omega$ \\
\hline Current amplitude (baseline) & $>0.2 \mathrm{nA}$ \\
\hline$R_{\text {SEAL stability }}$ & $<50 \%$ decrease \\
\hline Current stability & $<50 \%$ decrease in mean of vehicle control \\
\hline Voltage clamp quality & Visual inspection \\
\hline \multicolumn{2}{|c|}{ aTypical R }
\end{tabular}

${ }^{a}$ Typical $R_{\text {SEAL }}$ values ranged between 500 and $1,000 \mathrm{M} \Omega$. 
KURYSHEV ET AL.

Table 2. Acceptance Criteria for 384-Well

Population Patch Clamp Plate

Parameter

Acceptance criterion

$Z^{\prime}$ factor

$\geq 0.4$

SW

$\geq 2$

\begin{tabular}{l|l}
\hline Success rate & $>80 \%$ accepted wells per PPC plate
\end{tabular}

\begin{tabular}{l|l}
\hline$I_{50}$ for reference inhibitors & $\leq 0.5 \log$ from historical mean
\end{tabular}

SW, signal window; PPC, population patch clamp. where [Test] was the concentration of test article, $\mathrm{IC}_{50}$ was the concentration of the test article producing half-maximal inhibition, $N$ was the Hill coefficient, and \%Block was the mean value of percentage of the current inhibited at each concentration of a test article. Nonlinear least square fits were solved with the XLfit add-in for Excel 2003 (Microsoft).

\section{Acceptance Criteria}

Individual well data were filtered according to the criteria listed in Table 1 and the experiments were accepted based on the criteria listed in Table 2.

The $\mathrm{Z}^{\prime}$ factor and signal window (SW) in each experiment were calculated as follows:

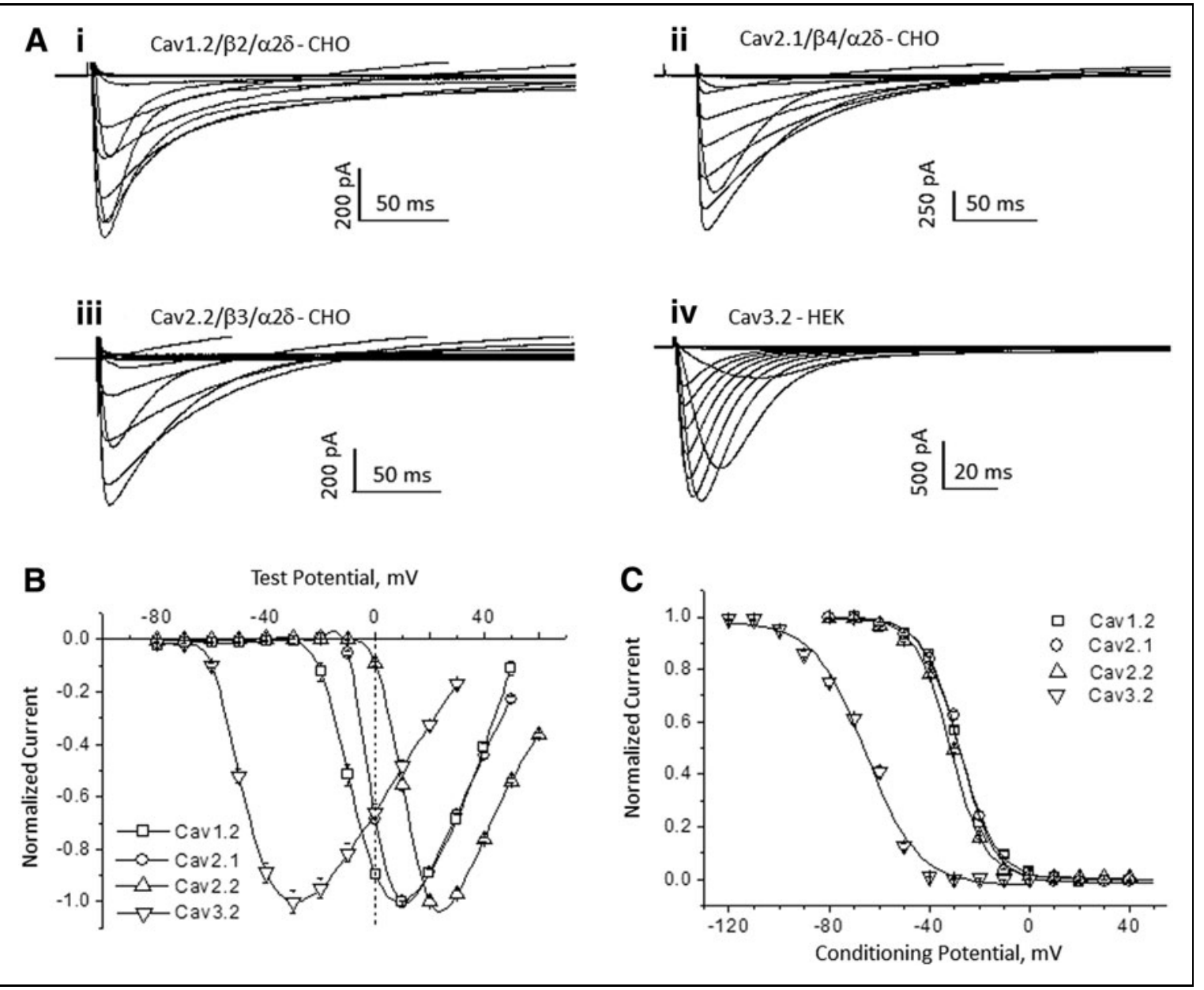

Fig. 1. Electrophysiological characteristics of $\mathrm{Ca}_{\mathrm{v}}$ channels in lonWorks ${ }^{\mathrm{TM}}$ Barracuda. (A, B) Voltage-dependent activation of channels. Calcium current families, where $7 \mathrm{mM} \mathrm{Ca}^{2+}$ is the charge carrier: $\mathrm{Ca}_{\mathrm{v}} 1.2$ (i), $\mathrm{Ca}_{\mathrm{v}} 2.1$ (ii), $\mathrm{Ca}_{\mathrm{v}} 2.2$ (iii), and $\mathrm{Ca}_{\mathrm{v}} 3.2$ (iv). Currents were elicited by applying test pulses from -80 to $+60 \mathrm{mV}$ in $10 \mathrm{mV}$ increments; the holding potential of $-80 \mathrm{mV}$ for Cav1.2 and $-90 \mathrm{mV}$ for other channels. In case of $\mathrm{Ca}_{\mathrm{v}} 3.2$, a $500-\mathrm{ms}$ conditioning voltage prepulse to $-120 \mathrm{mV}$ preceded each test pulse. The averaged current-voltage relationship is shown in (B) (mean $\pm \mathrm{SE} ; n=16$ ). Superimposition of steady-state inactivation curves of $\mathrm{Ca}_{\mathrm{v}}$ channels is illustrated in (C). The currents were elicited by $400 \mathrm{~ms}$ test pulses, after 1-s, the conditioning prepulses (CPs) ranged from -120 to $50 \mathrm{mV}$ (10 mV increments); the test pulse potentials were 10, 10, 30, and $-30 \mathrm{mV}$ for $\mathrm{Ca}_{\mathrm{v}} 1.2, \mathrm{Ca}_{\mathrm{v}}$ 2.1, $\mathrm{Ca}_{\mathrm{v}}$ 2.2, and $\mathrm{Ca}_{\mathrm{v}}$ 3.2 channels, respectively. 


$$
\begin{array}{r}
Z^{\prime}=1-\frac{3 \times \mathrm{SDVC}+3 \times \mathrm{SDPC}}{\mathrm{ABS}(\text { MeanVC }- \text { MeanPC })}, \\
\mathrm{SW}=\frac{(\text { MeanPC }-3 \times \mathrm{SDPC})-(\text { MeanVC }+3 \times \mathrm{SDVC})}{\mathrm{SDVC}},
\end{array}
$$

where MeanVC and SDVC are the mean and standard deviation values for a vehicle control, and MeanPC and SDPC are the mean and standard deviation values for a positive control.

\section{RESULTS}

We developed cell lines that express recombinant voltage-gated $\mathrm{Ca}^{2+}$ channels belonging to the $\mathrm{L}-, \mathrm{N}-, \mathrm{P} / \mathrm{Q}-$, and T-type classes: $\mathrm{hCa} \mathrm{a}_{\mathrm{v}} 1.2\left(\alpha_{1} \mathrm{C}\right)$ $\left.\beta_{2} / \alpha_{2} \delta_{1}\right), h a_{\mathrm{v}} 2.1\left(\alpha_{1} \mathrm{~A} / \beta_{4} / \alpha_{2} \delta_{1}\right), \mathrm{hCa} 2.2\left(\alpha_{1} \mathrm{~B} / \beta_{3} / \alpha_{2} \delta_{1}\right)$, and $\mathrm{hCa} 3.2$ $\left(\alpha_{1} \mathrm{H}\right)$, respectively; where $\alpha 1$ is the pore-forming subunit, and $\beta_{1-4}$ and $\alpha_{2} \delta_{1}$ are auxiliary subunits. Based on the relatively depolarized voltage range required to activate the channels, $\mathrm{Ca}_{\mathrm{v}} 1.2, \mathrm{Ca}_{\mathrm{v}} 2.1$, and $\mathrm{Ca}_{\mathrm{v}} 2.2$ are high-voltage-activated channels, whereas $\mathrm{Ca}_{\mathrm{v}} 3.2$ is activated at more negative membrane potentials and classified as a low-voltage-activated channel. Figure $1 \mathrm{~A}$ illustrates representative families of current traces for each channel recorded in IWB. Currents were evoked by voltage pulses that span the range from -80 to $+60 \mathrm{mV}$ in $10 \mathrm{mV}$ increments. The current-voltage relationships (Fig. 1B) show the expected separation of voltage ranges between the high- and low-voltage-activated channels. Thus, $\mathrm{hCa}_{\mathrm{v}} 1.2, \mathrm{hCa}_{\mathrm{v}} 2.2$, and $\mathrm{hCa}_{\mathrm{v}} 2.1$ show peak responses at positive membrane potentials, whereas $\mathrm{hCa}_{\mathrm{v}} 3.2$ peaks at about $-30 \mathrm{mV}$. All four channel subtypes display voltage-dependent inacti- vation during prolonged depolarization (Fig. 1A), as indicated by the return to baseline current. The voltage dependence of inactivation is plotted in Figure 1C. Steady-state inactivation curves fitted using the Boltzmann equation with half-inactivation $\left(\mathrm{h}_{0.5}\right)$ values were -65.8, - 31.6, - 27.4, and $-26.7 \mathrm{mV}$ for $\mathrm{Ca}_{\mathrm{v}} 3.2, \mathrm{Ca}_{\mathrm{v}} 2.2, \mathrm{Ca}_{\mathrm{v}} 2.1$, and $\mathrm{Ca}_{\mathrm{v}} 1.2$, respectively. Thus, as compared with the high-voltage-activated subtypes, inactivation of $\mathrm{Ca}_{\mathrm{v}} 3.2$ was shifted nearly $40 \mathrm{mV}$ toward more negative potentials. These results confirm that patch clamp recordings in the IWB platform can recapitulate the known voltage-dependent gating characteristics of these $\mathrm{Ca}^{2+}$ channel subtypes. Based on these results, we selected conditioning pulses that allow evaluation of statedependent inhibition and test pulse potentials that would be expected to minimize the effect of uncompensated series resistance error.

The channel subtypes also are distinguished on the basis of their pharmacological properties. The pore-forming $\alpha_{1}$ subunits confer selective sensitivity to most of the known activators and inhibitors (with the exception of gabapentin and pregabalin that bind the auxiliary $\alpha_{2} \delta$ subunit). In particular, $\mathrm{Ca}_{\mathrm{v}} 1.2$ and other L-type channels are sensitive to dihydropyridine activators (e.g., BAY K8644) and inhibitors (e.g., nifedipine). Other high-voltage-activated and all low-voltage-activated $\mathrm{Ca}^{2+}$ channels have low sensitivity to dihydropyridines. ${ }^{8}$ Figure 2 illustrates $\mathrm{Ca}_{\mathrm{v}} 1.2$ versus $\mathrm{Ca}_{\mathrm{v}} 2.2$ differences in dihydropyridine sensitivity. Current traces recorded pre- (vehicle; baseline) and postcompound addition show that $\mathrm{Ca}_{\mathrm{v}} 1.2$ currents (Fig. $2 A$-i) are completely blocked by $1 \mu \mathrm{M}$ nifedipine and potentiated by $0.3 \mu \mathrm{M}(S)-(-)$-BAY K8644. By contrast, peak $\mathrm{Ca}_{\mathrm{v}} 2.2$ (Fig. 2A-ii) current amplitude were unaffected by $1 \mu \mathrm{M}$ nifedipine (compared with vehicle control records). Similarly,

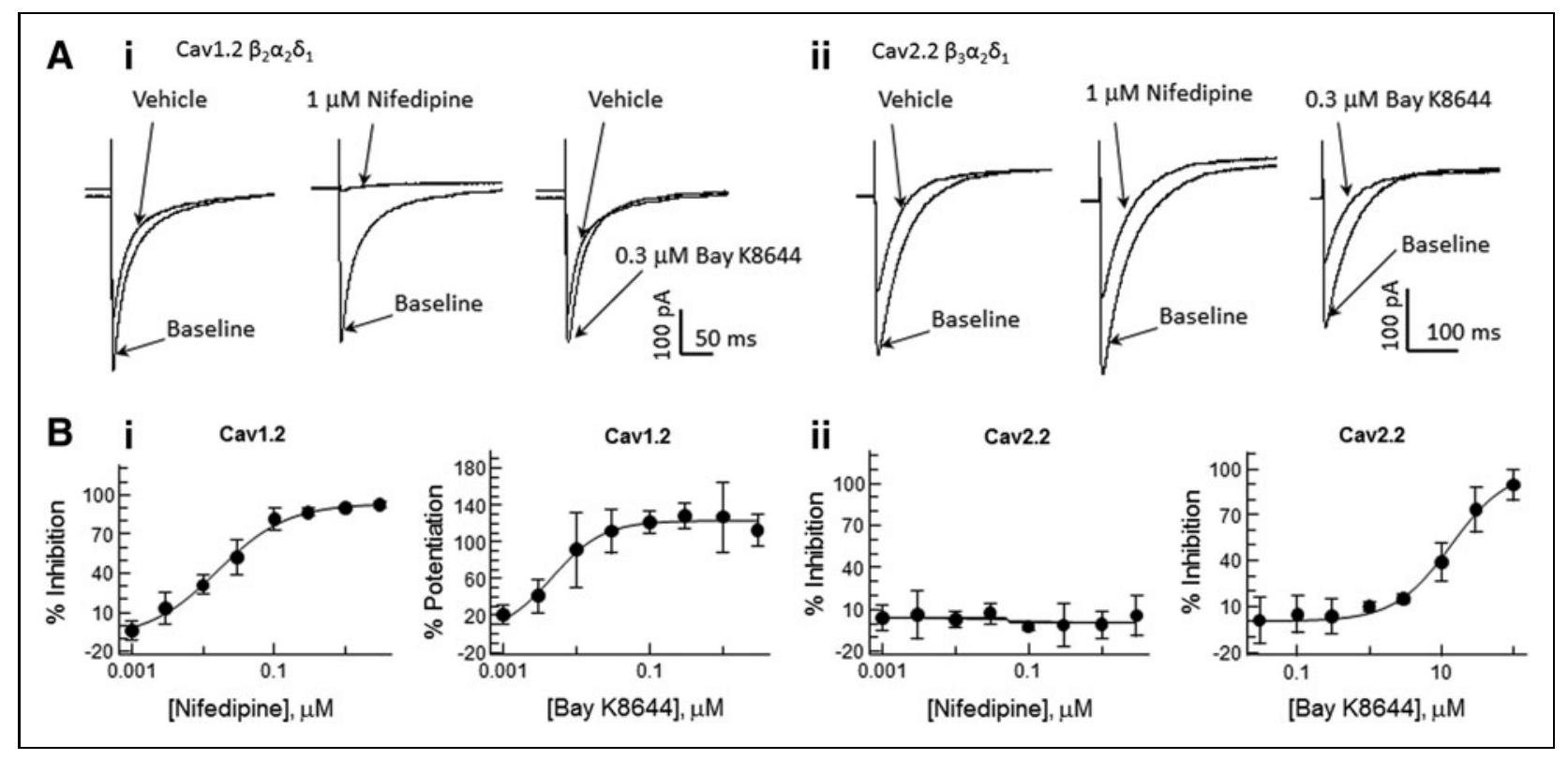

Fig. 2. Selectivity of pharmacological responses of $\mathrm{Ca}_{\mathrm{v}}$ subtypes to dihydropyridine compounds. (A) Representative current traces illustrating effects of nifedipine and BAY K8644 on $\mathrm{Ca}_{\mathrm{v}} 1.2$ (i) and $\mathrm{Ca}_{\mathrm{v}} 2.2$ (ii) channels. The currents were elicited with test pulses to $10 \mathrm{mV}$ $\left(\mathrm{Ca}_{\mathrm{v}} 1.2\right)$ and $30 \mathrm{mV}\left(\mathrm{Ca}_{\mathrm{v}} 2.2\right)$; the holding potential was $-90 \mathrm{mV}$ with $60-\mathrm{s} \mathrm{CP}$ to $-50 \mathrm{mV}$. (B) Dose-response curves of the compounds effect on $\mathrm{Ca}_{\mathrm{v}} 1.2$ (i) and $\mathrm{Ca}_{\mathrm{v}} 2.2$ (ii) channels. Data presented as mean $\pm \mathrm{SD} ; n=4$. Data were fit to the Hill equation with coefficient in the range 0.6-2.0. Nifedipine inhibited $\mathrm{Ca}_{\mathrm{v}} 1.2$ channels $\left(\mathrm{IC}_{50}=0.016 \mu \mathrm{M}\right)$ and had no effects on $\mathrm{Ca}_{\mathrm{v}} 2.2$ channels. BAY K8644 produced twofold potentiation of $C a_{v} 1.2$ channels $\left(E C_{50}=0.006 \mu \mathrm{M}\right)$, but inhibited $C a_{v} 2.2$ channel $\left(\mathrm{IC}_{50}=14.3 \mu \mathrm{M}\right)$. 
$\mathrm{Ca}_{\mathrm{v}} 2.1$ and $\mathrm{Ca}_{\mathrm{v}} 3.2$ channels were insensitive to nifedipine at concentrations up to $3 \mu \mathrm{M}$ (not shown). Conversely, BAY K8644, a dihydropyridine compound that potentiates the L-type channel current, increased the $\mathrm{Ca}_{\mathrm{v}} 1.2$ channel at low nanomolar concentrations $\left(\mathrm{EC}_{50}=6 \mathrm{nM}\right)$, but produced nonspecific inhibition of all four channels at concentrations $\geq 10 \mu \mathrm{M}$. Nifedipine block of $\mathrm{Ca}_{\mathrm{v}} 1.2$ and BAY K8644 block of $\mathrm{Ca}_{\mathrm{v}} 2.2$ were concentration dependent (Fig. 2B) with apparent $\mathrm{IC}_{50}$ values of $23 \mathrm{nM}$ and $13.6 \mu \mathrm{M}$, respectively.

To evaluate the pharmacological responses of $\mathrm{Ca}_{\mathrm{v}}$ channels in the IWB platform, we tested a set of well-characterized reference inhibitors (diltiazem, nifedipine, verapamil, mibefradil, and pimozide) for use- and/or voltage-dependent inhibition. The assays were optimized by testing several different voltage protocols to obtain the best balance between sensitivity and success rate. Examples of results obtained with two different voltage protocols are illustrated in Figure 3. A simple two-test pulse protocol (Fig. 3A) demonstrated the use de- pendence of $\mathrm{Ca}_{\mathrm{v}} 1.2$ inhibition with verapamil; the inhibitory potency detected by the second test pulse (TP2) was 3.5-times greater than that produced during the first test pulse (TP1). $\mathrm{IC}_{50}$ values were 35.3 and $9.1 \mu \mathrm{M}$, respectively, for TP1 and TP2. Similar results were obtained for diltiazem block of $\mathrm{Ca}_{\mathrm{v}} 1.2$ and mibefradil block of $\mathrm{Ca}_{\mathrm{v}} 2.2$ and $\mathrm{Ca}_{\mathrm{v}} 3.2$ channels (not illustrated). In contrast, inhibition of $\mathrm{Ca}_{\mathrm{v}} 1.2$ by nifedipine showed no use dependence in the two-test pulse protocol; the $\mathrm{IC}_{50}$ values were 0.59 and $0.57 \mu \mathrm{M}$, respectively, for the TP1 and TP2.

Because continuous (5-10 min) clamping of $\mathrm{Ca}_{\mathrm{v}} 1.2, \mathrm{Ca}_{\mathrm{v}} 2.1$, and $\mathrm{Ca}_{\mathrm{v}} 2.2$ cells at holding potentials of -50 or $-40 \mathrm{mV}$, as commonly done in native cells under voltage clamp, ${ }^{9}$ resulted in extensive run down of the currents, we used conditioning depolarizing prepulses to evaluate voltage-dependent inhibition in the IWB platform (Fig. 3B). In this voltage protocol, $\mathrm{Ca}_{\mathrm{v}} 1.2$ cells were held at $-80 \mathrm{mV}$ before stimulation. Test pulses were preceded by 50 -s conditioning steps to $-40 \mathrm{mV}$. The preconditioning enhanced the potency of $\mathrm{Ca}_{\mathrm{v}} 1.2$

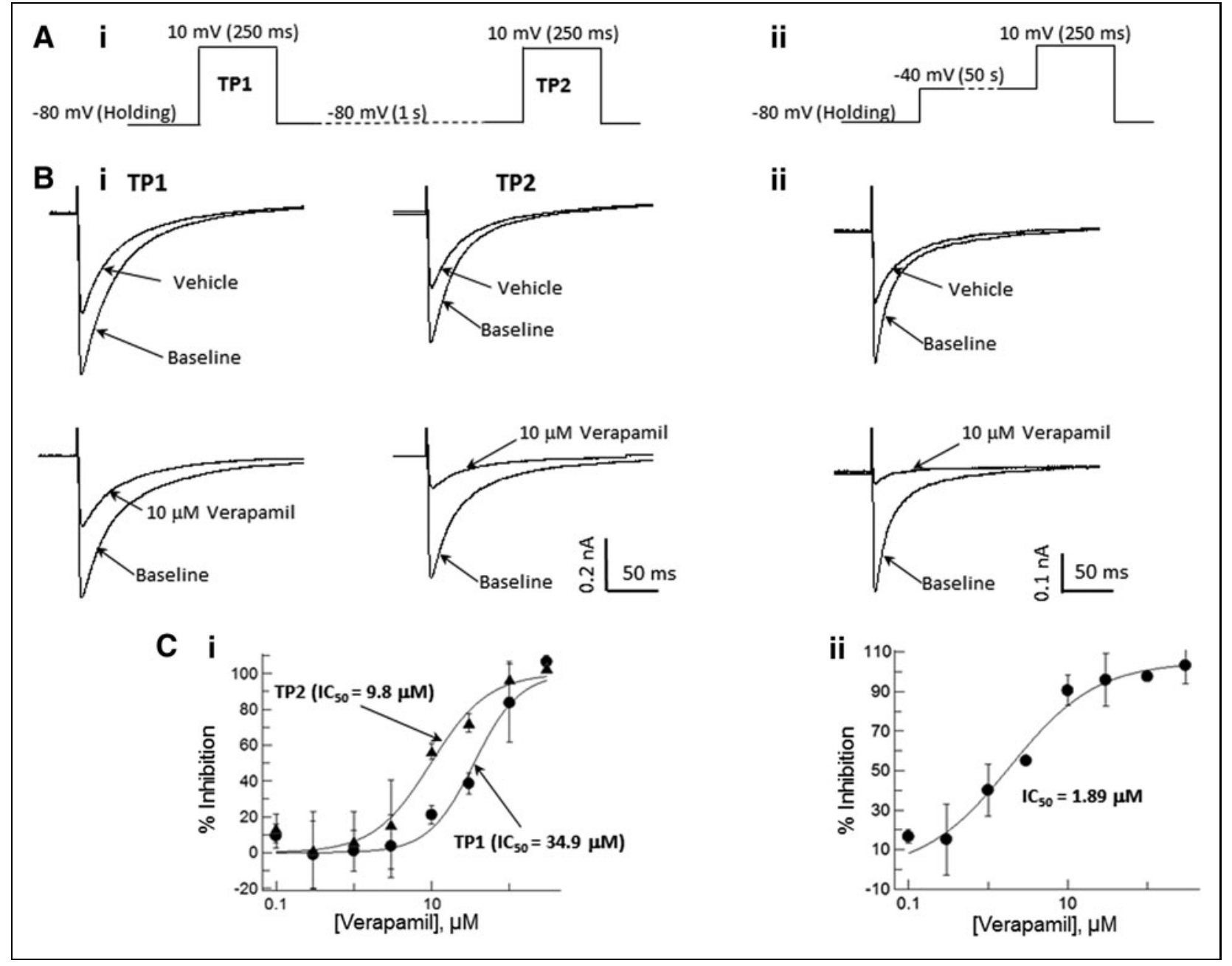

Fig. 3. Voltage and use dependence of $\mathrm{Ca}_{\mathrm{v}} 1.2$ block by verapamil. (A) Examples of voltage protocols used for detection of use-dependent (two-pulse protocol; i) and voltage-dependent (preconditioning protocol; ii) effects of verapamil. (B) Representative current traces for the two-pulse (i) and preconditioning (ii) voltage protocols. (C) Dose-response curves for $\mathrm{Ca}_{\mathrm{v}} \mathbf{1 . 2}$ inhibition by verapamil in the two-pulse (i) and preconditioning (ii) protocols. 


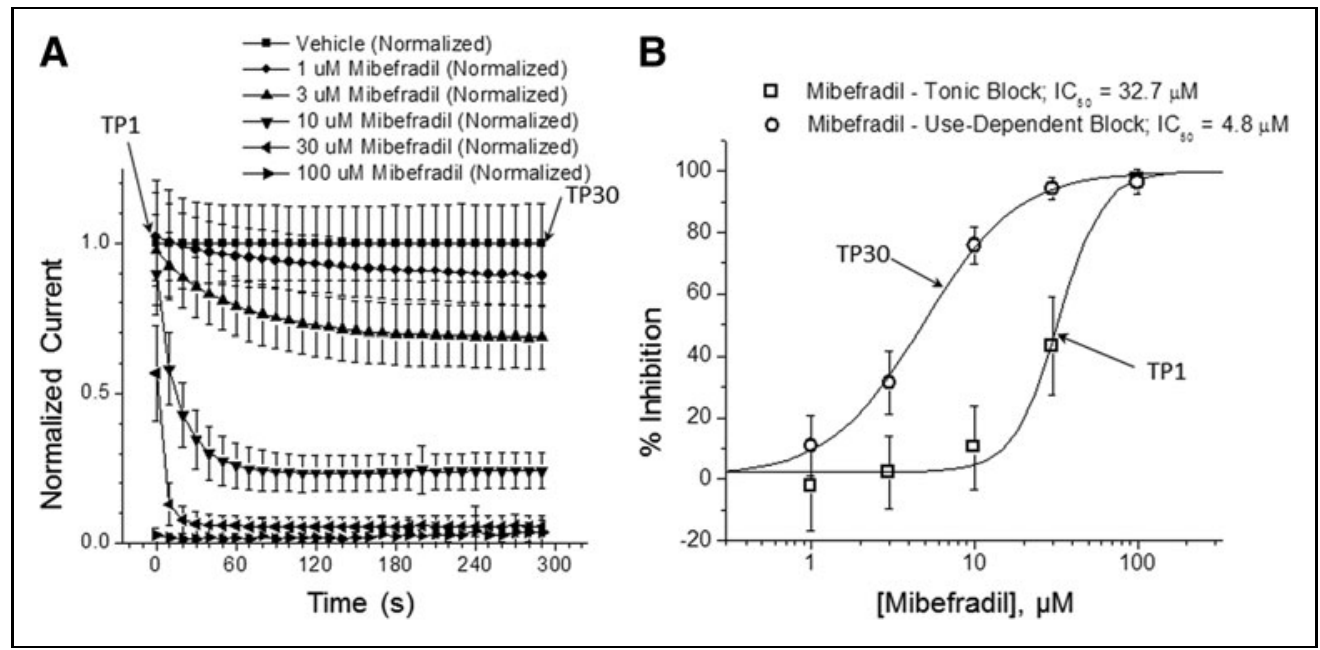

Fig. 4. Use-dependent block of $\mathrm{Ca}_{\mathrm{v}} 2.2$ by mibefradil. (A) Time course of $\mathrm{Ca}_{\mathrm{v}} 2.2$ inhibition with mibefradil during repetitive stimulation. The currents were elicited with test pulses to $+20 \mathrm{mV}$ from a holding potential $-90 \mathrm{mV}$ with $0.1 \mathrm{~Hz}$ frequency ( 30 stimulations in total); data were run down, corrected using time-matching vehicle control and presented as mean $\pm \mathrm{SD}$ ( $n=4$ per concentration). (B) Dose-response curves for the first (TP1) and last (TP30) stimulation test pulses (mean \pm SD). Mibefradil tonic block $\mathrm{IC}_{50}=32.7 \mu \mathrm{M}$, use-dependent block $\mathrm{IC}_{50}=4.8 \mu \mathrm{M}$.

inhibition compared with the two-test pulse protocol described above. $\mathrm{IC}_{50}$ values for the preconditioning protocol were 1.89, 0.013, and $2.43 \mu \mathrm{M}$, respectively, for verapamil, nifedipine, and diltiazem.

As an extension of the two-pulse voltage protocol, we evaluated use-dependent block augmentation by using stimulus patterns composed of repetitive test pulses. Figure 4 illustrates an experiment in which $\mathrm{Ca}_{\mathrm{v}} 2.2$ channels were stimulated by repetitive 400 ms test pulses to $+20 \mathrm{mV}$ from a holding potential $-90 \mathrm{mV}$ at frequency $0.1 \mathrm{~Hz}$ (30 test pulse train); mibefradil was added 5 min before stimulation by the TP1. Dose-response curves for the first (TP1) and last (TP30) test pulses were generated. Inhibition with mibefradil obtained at TP30 was about seven times more potent compared with the inhibition registered at $\mathrm{TP} 1 \mathrm{IC}_{50}$ values were 4.8 and $32.7 \mu \mathrm{M}$, respectively.

To utilize the highthroughput capabilities and increased stimulus flexibility in the IWB system, and to obtain more accurate prediction of both use- and voltage-dependent effects, we validated a multiple-mode voltage protocol that could be used with

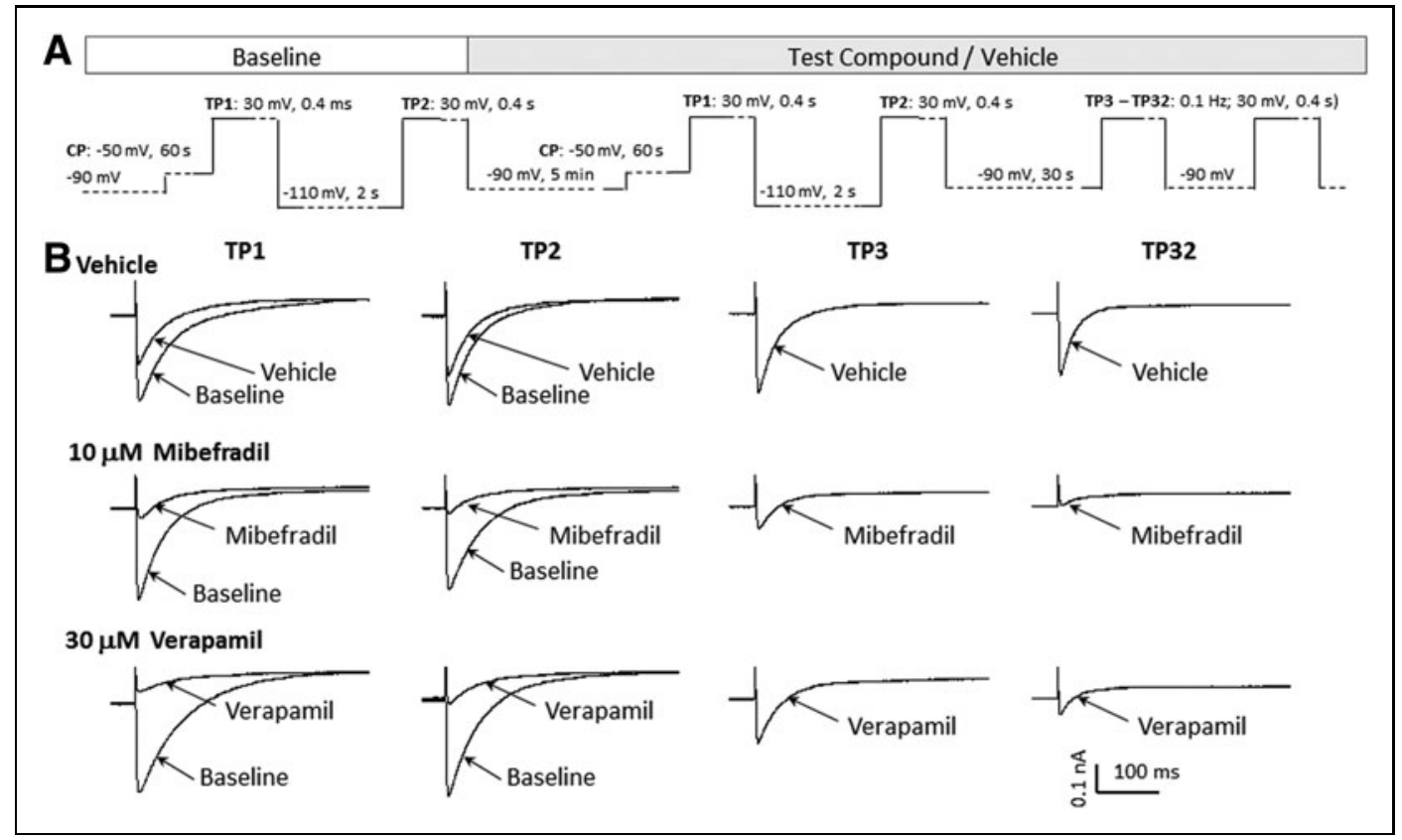

Fig. 5. Multiple mode voltage protocol for evaluation of voltage- and use-dependent block in $\mathrm{Ca}_{v}$ channels. (A) Optimized voltage protocol to detect use and voltage dependence of test compound interactions in $\mathrm{Ca}_{v}$ channels. (B) Representative $\mathrm{Ca}_{\mathrm{v}} 2.2$ current traces elicited with the voltage protocols before (baseline) and after addition of vehicle, $10 \mu \mathrm{M}$ mibefradil, and $30 \mu \mathrm{M}$ verapamil. 


\section{Table 3. Multiple Mode Voltage Protocol Parameters}

\begin{tabular}{|c|c|c|c|c|c|c|}
\hline Ion channel & $\begin{array}{l}\text { Holding } \\
\text { potential } \\
(\mathrm{mV})\end{array}$ & $\begin{array}{c}\mathrm{CP} \\
\text { potential } \\
(\mathrm{mV})\end{array}$ & $\begin{array}{c}\text { CP } \\
\text { duration } \\
\text { (s) }\end{array}$ & $\begin{array}{c}\text { TP potential } \\
\text { (TP1-TP32, mV) }\end{array}$ & $\begin{array}{c}\text { TP duration } \\
\text { (TP1-TP32, ms) }\end{array}$ & $\begin{array}{l}\text { TP frequency } \\
\text { (TP3-TP32, Hz) }\end{array}$ \\
\hline Cav1.2 & -90 & -50 & 60 & 10 & 250 & 0.1 \\
\hline Cav2.1 & -90 & -50 & 60 & 10 & 400 & 0.1 \\
\hline Cav2.2 & -90 & -50 & 60 & 30 & 400 & 0.1 \\
\hline Cav3.2 & -90 & -75 & 60 & -30 & 200 & 1 \\
\hline
\end{tabular}

$\mathrm{CP}$, conditioning prepulse; TP, test pulse.

\section{DISCUSSION}

Voltage-gated calcium $\left(\mathrm{Ca}_{\mathrm{v}}\right)$ channels activate as a function of membrane potential such that the probability of opening increases with membrane depolarization, but with prolonged depolarization the channels transit to a closed, inactivated state that can be both voltage and calcium dependent. Thus, changes in membrane potential pop-

the channels is evaluated by TP3 to TP32, consisting of a train of brief depolarizing pulses $(+30 \mathrm{mV}$ amplitude, $400 \mathrm{~ms}$ duration, from $-90 \mathrm{mV}$ holding potential, delivered repetitively at 10 -s intervals). It is noteworthy that TP3, the initial pulse in the train, is preceded by a $30-s$ conditioning interval at the holding potential $(-90 \mathrm{mV})$ and provides an alternative index of tonic block of the resting state. Block augmentation (postcompound addition) beyond the level attained in the resting state (i.e., use-dependent block) is measured by comparing peak current amplitudes, TP3 versus TP32, normalized to the effects of repetitive stimulation in channels exposed to vehicle alone. $\mathrm{Ca}_{\mathrm{v}} 2.2$ current traces elicited by the multiple mode assay (Fig. 5B) illustrate the blocking characteristics of mibefradil and verapamil. Mibefradil shows use-dependent, but not inactivation-dependent block augmentation. By contrast, verapamil shows both inactivation- and use-dependent block amounting to an approximately threefold increase in block compared with tonic levels at $-90 \mathrm{mV}$ preconditioning, as illustrated in Figure 6 that plots the concentration-response curves for each $\mathrm{Ca}_{\mathrm{v}}$ channel. Table 4 presents $\mathrm{IC}_{50}$ values for voltage- and use-dependent block in the multiple mode assay. In these experiments, calculation of the $Z^{\prime}$ statistic for TP1, using reference antagonists (Table 5) gave values exceeding 0.5 in each case, indicative of a robust assay. ${ }^{10}$ ulate different conformational states (closed, open, or inactivated) of the channel. It is well known that a drug binding to $\mathrm{Ca}_{\mathrm{v}}$ channels often shows state dependence such that the affinity of antagonist binding changes depending upon the channel conformation. ${ }^{11}$

The goal of this study was to develop patch clamp assays of recombinant calcium channels that take full advantage of the flexibility and throughput capabilities of the recently released IWB automated patch clamp system. We were able to optimize assays for state- and usedependent blocks in four different human $\mathrm{Ca}_{\mathrm{v}}$ subtypes using a standardized pulse protocol. It should be recognized that the standard protocol developed here provides a useful tool for evaluating $\mathrm{Ca}_{\mathrm{v}}$ subtype selectivity and for identifying dynamic characteristics of compounds, but may not be ideal for screening every class of compounds. For instance, compounds that require long exposure time or show a tendency to adsorb to the apparatus may require lengthened preincubation times and multiple applications at the expense of decreasing the number of data points that can be acquired per day. Therefore, in screening programs that require a high volume of output and rapid turnaround, pilot studies that allow further optimization for the classes of compounds to be tested and for the desired characteristics of the actives may be necessary. Another major consideration in designing an appropriate protocol would be data reduction and analysis. Our standard protocol yields

\section{Table 4. Pharmacology Summary: Reference Compound Potencies}

\begin{tabular}{|c|c|c|c|c|c|c|c|c|c|c|c|c|}
\hline \multirow[b]{2}{*}{$\begin{array}{l}\text { Reference } \\
\text { compound }\end{array}$} & \multicolumn{3}{|c|}{$\mathrm{Ca}_{\mathrm{v}} 1.2$} & \multicolumn{3}{|c|}{$\mathrm{Ca}_{\mathrm{v}} 2.1$} & \multicolumn{3}{|c|}{$\mathrm{Ca}_{\mathrm{v}} 2.2$} & \multicolumn{3}{|c|}{$\mathrm{Ca}_{\mathrm{v}} 3.2$} \\
\hline & $\begin{array}{l}\text { Pre-pulse } \\
-50 \mathrm{mV}\end{array}$ & $\begin{array}{c}\text { Pre-pulse } \\
-90 \mathrm{mV}\end{array}$ & $0.1 \mathrm{~Hz}$ & $\begin{array}{l}\text { Pre-pulse } \\
-50 \mathrm{mV}\end{array}$ & $\begin{array}{l}\text { Pre-pulse } \\
-90 \mathrm{mV}\end{array}$ & $0.1 \mathrm{~Hz}$ & $\begin{array}{l}\text { Pre-pulse } \\
-50 \mathrm{mV}\end{array}$ & $\begin{array}{l}\text { Pre-pulse } \\
-90 \mathrm{mV}\end{array}$ & $0.1 \mathrm{~Hz}$ & $\begin{array}{c}\text { Pre-pulse } \\
-75 \mathrm{mV}\end{array}$ & $\begin{array}{c}\text { Pre-pulse } \\
-90 \mathrm{mV}\end{array}$ & $1 \mathrm{~Hz}$ \\
\hline Verapamil & $6.5 \pm 1.5$ & $25.3 \pm 5.2$ & $5.3 \pm 1.1$ & $5.0 \pm 1.1$ & $22.1 \pm 4.7$ & $12.4 \pm 3.6$ & $13.1 \pm 2.7$ & $46.0 \pm 8.7$ & $17.8 \pm 3.1$ & $14.3 \pm 3.3$ & $21.2 \pm 3.8$ & $12.7 \pm 1.8$ \\
\hline Nifedipine & $0.023 \pm 0.007$ & $0.085 \pm 0.026$ & $0.10 \pm 0.013$ & $>3.0$ & $>3.0$ & $>3.0$ & $>3.0$ & $>3.0$ & $>3.0$ & $>3.0$ & $>3.0$ & $>3.0$ \\
\hline BAY K8644 & $(0.006 ; 0.005)^{a}$ & ND & ND & $5.4 \pm 0.9$ & $24.8 \pm 7.3$ & $10.0 \pm 2.6$ & $(13.6,14.3)$ & $(54.7,37.2)$ & $(17.3,16.1)$ & $10.8 \pm 1.9$ & $11.5 \pm 0.6$ & $7.2 \pm 0.7$ \\
\hline Pimozide & $>30.0$ & $27.8 \pm 9.8$ & $1.9 \pm 0.6$ & $>30.0$ & $>30.0$ & $>30.0$ & $>30.0$ & $>30.0$ & $>30.0$ & $8.9 \pm 3.6$ & $7.2 \pm 1.2$ & $5.5 \pm 1.3$ \\
\hline Mibefradil & $10.8 \pm 3.10$ & $16.1 \pm 4.6$ & $8.0 \pm 1.8$ & $6.5 \pm 1.2$ & $4.0 \pm 1.1$ & $2.2 \pm 0.6$ & $10.8 \pm 1.3$ & $8.4 \pm 2.1$ & $3.0 \pm 0.2$ & $3.30 \pm 0.9$ & $3.7 \pm 1.0$ & $2.0 \pm 0.9$ \\
\hline
\end{tabular}

Data are mean \pm SD $I C_{50} S$ (in $\mu \mathrm{M}$ ) from three to four experiments; where only two experiments were run, data from each experiment are listed.

${ }^{\mathrm{a}} \mathrm{EC}_{50}, \mathrm{BAY} \mathrm{K} 8644$ potentiated $\mathrm{Ca}_{\mathrm{v}} 1.2$.

ND, not determined. 

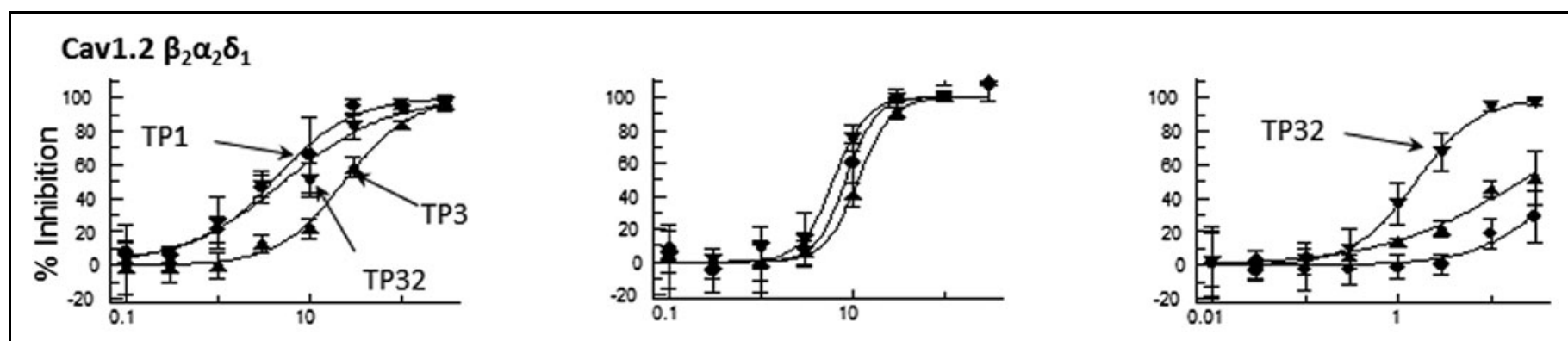

Cav2.1 $\beta_{4} \alpha_{2} \delta_{1}$
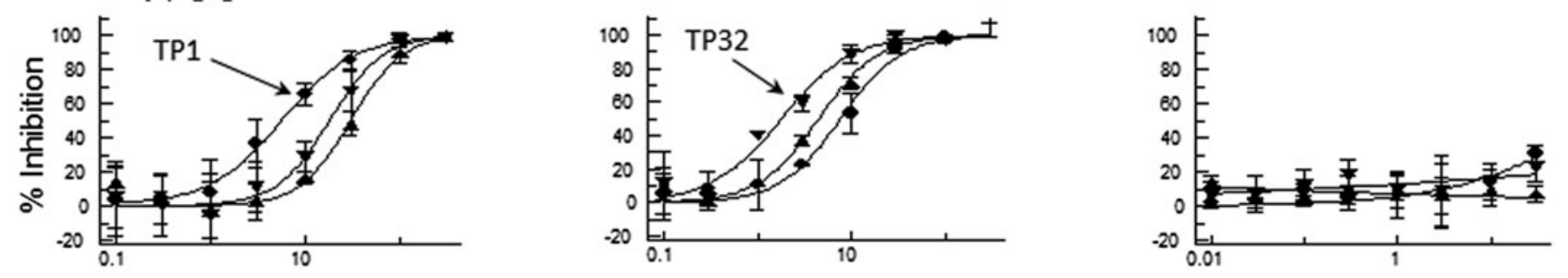

Cav2.2 $\beta_{3} \alpha_{2} \delta_{1}$
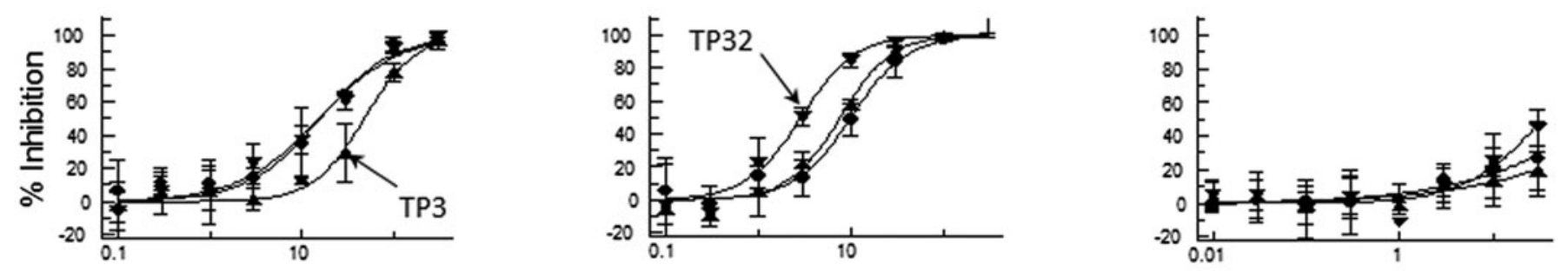

\section{Cav3.2}
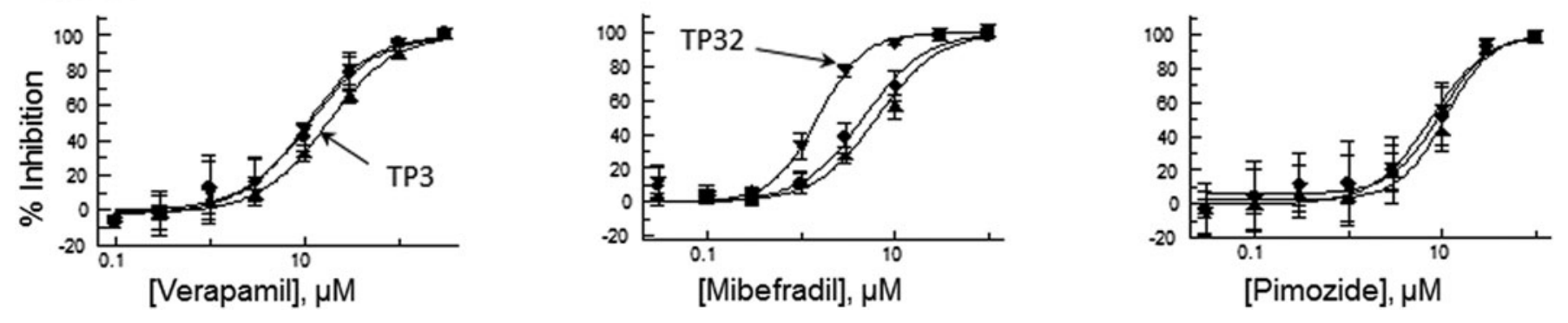

Fig. 6. Voltage- and use-dependent block of $\mathrm{Ca}_{\mathrm{v}}$ channels by reference compounds recorded in the multiple mode protocol. Dose-response curves for verapamil, mibefradil, and pimozide, multiple mode assay protocol. The voltage protocol is shown in Figure 5; specific voltage parameters for each $\mathrm{Ca}_{v}$ channel are presented in Table 3. For each test compound and $\mathrm{Ca}_{v}$ channel target, three curves are superimposed: TP1 (circles) - the curve generated at the test pulse after the $\mathrm{CP}, \mathrm{TP}_{3}$ (triangles) - the curve generated at the first test pulse from the holding potential, and TP32 (inverted triangles) - the curve generated at the last test pulse from the holding potential. $\mathrm{IC}_{50}$ values for the curves are presented in Table 4 .

multiple endpoints that enable evaluation of state- and use-dependent block, but complicate the analysis and may not be essential for highvolume screening.

Our validation experiments yielded state-and use-dependent $\mathrm{IC}_{50}$ values of reference compounds in all four $\mathrm{Ca}_{\mathrm{v}}$ channels, as presented in Table 4. These results highlight the differences between the channel subtypes. For instance, the dihydropyridine compounds nifedipine and antagonist, and BAY K8644, a potenti- ator, were effective in these roles only in $\mathrm{Ca}_{\mathrm{v}} 1.2$. Other compounds showed less subtype selectivity. Thus, mibefradil, a use-dependent blocker that was originally described as a selective T-type channel antagonist and later shown to be a mixed T/L-blocker, ${ }^{12}$ was observed in our experiments to be equipotent in the use-dependent evaluation of $\mathrm{Ca}_{\mathrm{v}} 2.1, \mathrm{Ca}_{\mathrm{v}} 2.2$, and $\mathrm{Ca}_{\mathrm{v}}$ 3.2. Nonetheless, mibefradil's use-dependent block was fourfold more potent in $\mathrm{Ca}_{\mathrm{v}} 3.2$ versus $\mathrm{Ca}_{\mathrm{v}} 1.2$, in agreement with published reports of $\mathrm{Ca}_{\mathrm{v}} 3.2$ selectivity 


\section{KURYSHEV ET AL.}

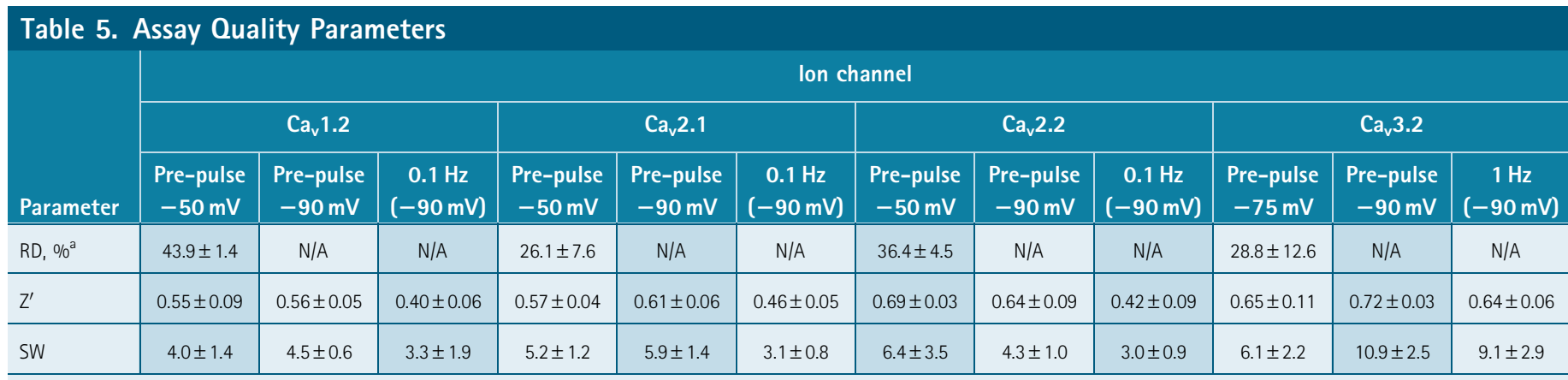

Reference compounds for calculating $Z^{\prime}$ and SW were verapamil (Cav 1.2, Cav2.1, Cav 2.2) or mibefradil (Ca 3.2$)$.

${ }^{\mathrm{a}} \mathrm{RD}$ was measured at TP1 in time-matched vehicle control wells.

RD, run down; TP1, test pulse 1 .

over $\mathrm{Ca}_{\mathrm{v}} 1.2$ reported by Martin et al. in manual patch clamp experiments. ${ }^{13}$ However, our $\mathrm{Ca}_{\mathrm{v}} 3.2 \mathrm{IC}_{50}$ value obtained with $-90 \mathrm{mV}$ prepulse (Table 4) was approximately sixfold higher than that reported by Martin et al. ${ }^{13}$ The use dependence of mibefradil may account for this discrepancy. As is typical in manual patch clamp, the onset of block was evaluated by repetitive stimulation at $0.1 \mathrm{~Hz}$ until a steady-state effect was observed, ${ }^{13}$ allowing cumulative usedependent block, whereas in the IWB assay, stimulation was performed only once after exposure to the test compound for a fixed interval. Nonetheless, in IWB, by stimulating with a brief high-frequency train, we were able to achieve an $\mathrm{IC}_{50}$ value of 2.0 (Table 4, $\mathrm{Ca}_{\mathrm{v}} 3.2,1 \mathrm{~Hz}$ stimulus frequency) similar to that observed in manual patch clamp. ${ }^{13}$ This comparison of manual and automated patch clamp highlights the importance of recognizing the limitations of automated platforms and developing procedures that accommodate differences in the blocking kinetics and state-dependent characteristics of test compounds, as noted by others previously in $\mathrm{Ca}_{\mathrm{v}} 2.2$ assays. $^{14}$

Pimozide also has been described as a T-type channel inhibitor ${ }^{15}$ and our evaluation of tonic block is consistent with this characterization. However, we found that pimozide's selectivity for $\mathrm{Ca}_{\mathrm{v}} 3.2$ over $\mathrm{Ca}_{\mathrm{v}} 1.2$ disappeared in the use-dependent assay, which gave $\mathrm{IC}_{50}$ values of 4.6 and $1.6 \mu \mathrm{M}$, respectively, in the two channel subtypes. As expected from the literature, ${ }^{16}$ we found that verapamil was relatively nonselective. It showed a twofold to fivefold increase in potency for state-dependent block in the high-voltage-activated subtypes and state-independent block of the low-voltage-activated channel $\left(\mathrm{Ca}_{\mathrm{v}} 3.2\right)$.

Several studies of $\mathrm{Ca}_{\mathrm{v}}$ channels in automated patch clamp have been published recently. Most notably, IonWorks Quattro (IWQ, the predecessor to IWB) has been used in $\mathrm{Ca}_{\mathrm{v}} 1.2$ recording with results comparable to those described here. For instance, Morton and Main ${ }^{17}$ reported a verapamil $\mathrm{IC}_{50}$ value of $3.3 \mu \mathrm{M}$ (at a holding potential of $-60 \mathrm{mV}$ ), similar to the $4.3 \mu \mathrm{M} \mathrm{IC} \mathrm{I}_{50}$ value reported here (Table 4, prepulse $-50 \mathrm{mV}$, holding potential, $-90 \mathrm{mV}$ ). Interestingly, Cao et $a l .{ }^{18}$ also reported a verapamil $\mathrm{IC}_{50}$ value of $4.0 \mu \mathrm{M}$, but at a holding potential of $-90 \mathrm{mV}$, whereas we observed a marked de- crease in potency $\left(\mathrm{IC}_{50}=24.2 \mu \mathrm{M}\right.$, Table 4, prepulse and holding potential, $-90 \mathrm{mV}$ ) under these conditions. This discrepancy may reflect the discontinuous voltage clamp characteristic of IWQ, which allows cells to be depolarized between voltage clamp recordings. Therefore, the continuous voltage clamp feature of IWB may be particularly important for characterizing the state and voltage dependence of $\mathrm{Ca}_{\mathrm{v}}$ inhibitors.

Our $\mathrm{Ca}_{\mathrm{v}} 1.2$ results (verapamil $\mathrm{IC}_{50}=4.2 \mu \mathrm{M}$ and nifedipine $\mathrm{IC}_{50}=$ $0.016 \mu \mathrm{M}$, Table 4) also can be compared with data obtained in gigaohm seal automated instruments such as PatchXpress ${ }^{\circledR}$ (Molecular Devices Corporation), where $\mathrm{IC}_{50}$ values of 15 and $0.016 \mu \mathrm{M}$, respectively, were obtained for verapamil and nifedipine. ${ }^{19}$

In conclusion, we have demonstrated that the advanced capabilities of a high-throughput automated patch clamp, including flexible voltage stimulation patterns, continuous voltage clamp, and rapid throughput, provide a suitable platform to support quantitative drug evaluation of potency, state and use dependence, and subtype selectivity in the therapeutically important voltage-gated $\mathrm{Ca}^{2+}$ channel family.

\section{ACKNOWLEDGMENTS}

We would like to thank Zhiqi Liu and Hung Lee (ChanTest Corporation) for their assistance in cell line development and IWB validation.

\section{DISCLOSURE STATEMENT}

No competing financial interests exist.

\section{REFERENCES}

1. Catterall WA, Perez-Reyes E, Snutch TP, Striessnig J: International Union of Pharmacology. XLVIII. Nomenclature and structure-function relationships of voltage-gated calcium channels. Pharmacol Rev 2005;57:411-425.

2. Triggle DJ: Drug targets in the voltage-gated calcium channel family: why some are and some are not. Assay Drug Dev Technol 2003;1:719-733.

3. Snutch TP: Targeting chronic and neuropathic pain: the N-type calcium channel comes of age. NeuroRx 2005;2:662-670. 
4. McGivern JG, McDonough SI: Voltage-gated calcium channels as targets for the treatment of chronic pain. Curr Drug Targets CNS Neurol Disord 2004;3: 457-478.

5. Gomora JC, Daud AN, Weiergräber M, Perez-Reyes E: Block of cloned human Ttype calcium channels by succinimide antiepileptic drugs. Mol Pharmacol 2001;60:1121-1132.

6. Field MJ, Hughes J, Singh L: Further evidence for the role of the $\alpha_{2} \delta$ subunit of voltage dependent calcium channels in models of neuropathic pain. $\mathrm{Br} J$ Pharmacol 2000;131:282-286.

7. Wible BA, Kuryshev YA, Smith SS, Liu Z, Brown AM: An ion channel library for drug discovery and safety screening on automated platforms. Assay Drug Dev Technol 2008;6:765-780.

8. Doering CJ, Zamponi GW: Molecular pharmacology of high voltage-activated calcium channels. J Bioenerg Biomembr 2003;35:491-505.

9. Sanguinetti MC, Kass RS: Voltage-dependent block of calcium channel current in the calf cardiac Purkinje fiber by dihydropyridine calcium channel antagonists. Circ Res 1984;55:336-348.

10. Zhang $\mathrm{JH}$, Chung TD, Oldenburg KR: A simple statistical parameter for use in evaluation and validation of high throughput screening assays. J Biomo/ Screen 1999;4:67-73.

11. Hondeghem LM, Katzung BG: Antiarrhythmic agents: the modulated receptor mechanism of action of sodium and calcium channel-blocking drugs. Annu Rev Pharmacol Toxicol 1984;24:387-423.

12. Mehrke G, Zong XG, Flockerzi V, Hofmann F: The $\mathrm{Ca}^{2+}$-channel blocker Ro 405967 blocks differently T-type and L-type $\mathrm{Ca}^{2+}$ channels. J Pharmacol Exp Ther 1994;271:1483-1488

13. Martin RL, Lee $J H$, Cribbs LL, Perez-Reyes E, Hanck DA: Mibefradil block of cloned T-type calcium channels. J Pharmacol Exp Ther 2000;295:302-308.

14. Swenson AM, Niforatos W, Vortherms TA: An automated electrophysiological assay for differentiating Cav2.2 inhibitors based on state dependence and kinetics. Assay Drug Dev Technol 2012;10:542-550.

15. Santi CM, Cayabyab FS, Sutton KG, et al:: Differential inhibition of T-type calcium channels by neuroleptics. J Neurosci 2002;22:396-403.

16. Lacinová L: Voltage-dependent calcium channels. Gen Physiol Biophys 2005;24 Suppl 1:1-78.

17. Morton MJ, Main MJ: Use of escin as a perforating agent on the lonWorks Quattro automated electrophysiology platform. J Biomol Screen 2013;18: $128-134$
18. Cao $X$, Lee $Y T$, Holmqvist $M$, Lin $Y$, et al.: Cardiac ion channel safety profiling on the lonWorks Quattro automated patch clamp system. Assay Drug Dev Technol 2010;8:766-780.

19. Balasubramanian $B$, Imredy JP, Kim $D$, et al.: Optimization of $C a_{v} 1.2$ screening with an automated planar patch clamp platform. J Pharmacol Toxicol Methods 2009;59:62-72.

Address correspondence to: Glenn E. Kirsch, PhD ChanTest Corporation 14656 Neo Parkway Cleveland, $\mathrm{OH} 44128$

E-mail: gkirsch@chantest.com

\section{Abbreviations Used}

\section{$\mathrm{CHO}=$ chinese hamster ovary}

$\mathrm{CP}=$ conditioning prepulse

DMEM/F-12 = Dulbecco's modified Eagle's medium/nutrient mixture F-12 DMSO $=$ dimethyl sulfoxide

$h_{0.5}=$ half-inactivation

HB-PS $=$ HEPES-buffered physiological saline

HBSS $=$ Hank's Balanced Salt Solution

hCa $\mathrm{a}_{\mathrm{v}} 1.2=$ human $\mathrm{Ca}_{\mathrm{v}} 1.2$

hCa $2.1=$ human $\mathrm{Ca}_{\mathrm{v}} 2.1$

hCav $2.2=$ human $\mathrm{Ca}_{\mathrm{v}} 2.2$

hCa $3.2=$ human $\mathrm{Ca}_{\mathrm{v}} 3.2$

HEK = human embryonic kidney

IWB $=$ lonWorks ${ }^{\mathrm{TM}}$ Barracuda

IWO $=$ lonWorks Quattro

$\mathrm{PPC}=$ population patch clamp

$\mathrm{SW}=$ signal window

TP1 $=$ first test pulse

TP2 $=$ second test pulse

TP30 $=$ last test pulse 